\title{
Pengaruh Minat Kunjung Pemustaka di Perpustakaan “Puspa Cendekia" SD Negeri Pakis 1
}

\author{
Husnatun Inabah \\ Perpustakaan Sekolah Dasar Negeri Pakis 1 \\ email: inanikeke9@gmail.com
}

\begin{abstract}
Abstrak
Jantung dari pendidikan sekolah adalah perpustakaan. Pendidikan yang berkualitas senantiasa ditumbuhkembangkan melalui perpustakaan. Perpustakaan dapat dimanfaatkan secara optimal apabila perpustakaan menyediakan berbagai informasi dari bahan pustaka yang dimiliki baik dalam bentuk cetak maupun terekam. Kelengkapan koleksi dan fasilitas yang tersedia sangat mempengaruhi daya tarik pemustaka untuk mengunjungi perpustakaan. Peningkatan jumlah pengunjung menunjukkan bahwa perpustakaan dapat memberikan pelayanan prima. Penggunaan software SLIMS memberikan kemudahan dalam pelayanan peminjaman dan pengembalian buku. Penelitian ini bertujuan untuk memahami unsur yang menyebabkan minat kunjung siswa ke pe perpustakaan Puspa Cendekia. Metode penelitian yang digunakan observasi dan wawancara. Mengamati dan mencatat secara sistematik keadaan perpustakaan Puspa Cendekia dari berbagai sudut pandang seperti ruangan, koleksi yang dimiliki, fasilitas, pelayanan. Selain itu penulis juga melakukan wawancara dengan pustakawan dan beberapa siswa pengunjung perpustakaan. Penelitian ini membuktikan bahwa unsur yang menyebabkan minat kunjung siswa karena pelayanan ramah, ruang perpustakan yang nyaman dengan adanya fasilitas AC, koleksi yang cukup lengkap, serta fasilitas yang memadai. Dari hasil penelitian dapat diambil kesimpulan bahwa pengaruh minat kunjung pemustaka dipengaruhi oleh beberapa unsur, antara lain tersedianya koleksi yang cukup lengkap, ruangan yang nyaman, pelayanan pengguna sangat memuaskan. Namun ada juga kendala yang dihadapi pustakawan yaitu belum tersedianya jaringan internet, dana anggaran BOS sebesar 5\% untuk perpustakaan belum terealisasi sepenuhnya, kurangnya kesadaran pengguna untuk mengembalikan buku ke rak sesuai dengan nomor klasifikasinya setelah mereka selesai membaca.
\end{abstract}

\author{
Kata kunci : \\ Perpustakaan, \\ Pemustaka, \\ Kunjungan, \\ Perpustakaan Puspa \\ Cendekia,
}

\section{A. PENDAHULUAN}

Hakekat perpustakaan sekolah adalah sebagai pusat belajar dan sumber informasi bagi warga sekolah (Darmono, 2007). Perpustakaan memberikan sumbangan yang sangat besar untuk kualitas pendidikan dalam kegiatan belajar mengajar di sekolah. Untuk menunjang pencapaian tujuan sekolah, perpustakaan menyajikan bahan pustaka berupa buku dan non buku yang disusun secara sistematis sehingga memudahkan pemustaka dalam penggunaannya. Saat ini untuk memperoleh informasi sangat mudah, tidak hanya melalui buku tetapi juga melaui internet. Cukup dengan mengetik kata kunci, informasi yang dicari sudah tersedia di internet.

Minat membaca menjadi suatu permasalahan di lingkungan masyarakat karena keinginan membacanya masih rendah. Akan tetapi, berbeda dengan keadaaan yang ada di perpustakaan Puspa Cendekia, siswa maupun guru memiliki kesadaran untuk membaca karena kebutuhan informasi. Rata-rata pengunjung setiap harinya 57 orang yang terdiri dari siswa, guru dan karyawan.

Tujuan pemustaka mengunjungi perpustakaan tidak hanya untuk meminjam buku, tetapi ada juga diantara mereka yang membaca dan mengerjakan tugas di perpustakaan. Guru memanfaatkan perpustakaan untuk tempat pembelajaran 
diluar kelas dan memberikan tugas dengan topik tertentu yang sumbernya ada di perpustakaan.

Ada beberapa unsur yang menjadi pengaruh minat kunjung pemustaka ke perpustakaan. Oleh karena itu, penulis akan membahas mengenai perpustakaan sekolah di SD Negeri Pakis 1 dengan judul "Pengaruh Minat Kunjung Pemustaka di Perpustakaan Puspa Cendekia SD Negeri Pakis 1."

Riset ini akan menguji secara empiris terkait dengan:

a. Apa yang mempengaruhi minat kunjung pemustaka di Perpustakaan Puspa Cendekia?

b. Apa yang menjadi kendala Perpustakaan Puspa Cendekia dalam menangani banyaknya pengunjung?

c. Bagaimana solusi yang dilakukan pustakawan perpustakaan Puspa Cendekia dalam mengatasi banyaknya jumlah pengunjung?

Ruang lingkup penelitian ini akan membahas tentang pelayanan, koleksi perpustakaan, fasilitas, pengelolaan, tata ruang perpustakaan. Sementara penelitian ini bertujuan untuk membuktikan dan mengetahui: (1) hal-hal yang dapat mempengaruhi minat kunjung pemustaka. (2) tujuan pemustaka mengunjungi perpustakaan. (3) kendala-kendala yang dihadapi pustakawan. (4) solusi dari kendala yang dihadapi pustakawan.

Penelitian ini diharapkan bermanfaat untuk meningkatkan kinerja pustakawan dalam melayani banyaknya pengunjung dengan berbagai tujuan mengunjungi perpustakaan.

\section{B. KAJIAN PUSTAKA}

Hasil riset Saidat Abiola Fakoya-Michael dan Michael Bamidele Fakoya menyebutkan bahwa tingkat perlindungan perpustakaan di antara mahasiswa akuntansi diperiksa baik dalam jarak dan lembaga pembelajaran kontak di Afrika Selatan (Fakoya-Michael \& Fakoya, 2020). Kami menggu- nakan kuesioner terstruktur untuk mengumpulkan data dari sampel 500 mahasiswa akuntansi dari kejauhan dan lembaga pembelajaran kontak di Afrika Selatan, di mana 379 mengembalikan kuesioner yang diisi, mewakili 76\%. Temuan menunjukkan apatis di antara mahasiswa akuntansi universitas Afrika Selatan terhadap perlindungan layanan perpustakaan, yang diperburuk oleh praktik dosen dalam memberikan tugas yang tidak mengharuskan siswa untuk mencari informasi di luar apa yang ada dalam buku teks yang mereka rekomendasikan. Faktor paling signifikan yang memengaruhi perlindungan mahasiswa terhadap sumber daya perpustakaan di universitas akuntansi adalah keahlian dan interaksi dengan staf perpustakaan. Ini menegaskan Teori Ekspektasi-Konfirmasi bahwa mahasiswa akuntansi dari kedua lembaga diperiksa berdasarkan tingkat kepuasan mereka pada persepsi mereka tentang layanan perpustakaan yang mereka terima. Manajemen perpustakaan membutuhkan pemahaman tentang praktik pengajaran dan pembelajaran dari disiplin akuntansi dan bekerja sama dengan pengembang kurikulum untuk meningkatkan penggunaan sumber daya perpustakaan oleh siswa akuntansi. Di masa depan, jumlah universitas yang menawarkan program akuntansi di Afrika Selatan perlu diperluas dan agar perpustakaan universitas dapat memenuhi jumlah mahasiswa akuntansi yang lebih tinggi. Peneliti lain Abdulghani Muthanna dan Guoyuan Sang menyatakan, bahwa studi ini menyediakan platform dasar dari mana penelitian lebih lanjut ke perpustakaan universitas sangat mendesak. Penelitian semacam itu akan memberikan berbagai wawasan dan gagasan untuk meningkatkan penyediaan sumber daya dan layanan. Temuan studi dengan jelas melaporkan bahwa perpustakaan universitas di Yaman tetap tradisional, terletak di dalam gedung-gedung perguruan tinggi yang ada, memiliki dua ruangan atau lebih yang 
mengandung sumber daya usang yang dikelola secara acak, dan mempekerjakan sangat sedikit staf - beberapa di antaranya tidak memiliki gelar sarjana di bidang kepustakawanan atau pelatihan yang memadai tentang bekerja secara efisien dalam lingkungan perpustakaan (Muthanna \& Sang, 2019). Perpustakaan tradisional di Yaman dan struktur manajemen tradisional memberi siswa dan guru sikap negatif terhadap perpustakaan. Lebih jauh lagi, kurangnya informasi dan sumber daya yang berkualitas memperdalam perspektif pesimistis semacam itu. Hampir satu dekade telah berlalu sejak diluncurkannya 'strategi nasional untuk pengembangan pendidikan tinggi' dan tidak ada koleksi modern atau sistem berbasis elektronik. Hal ini menyebabkan banyak tantangan untuk mengajar dosen dan melatih guru siswa menggunakan perpustakaan untuk melakukan penelitian. Tantangan seperti itu juga membuat mahasiswa dan profesor menghindari masuk perpustakaan dan memanfaatkan sumber daya yang ada. Kondisi perpustakaan universitas di Yaman menyedihkan. Meskipun ada dua dewan universitas yang lebih tinggi yang membahas masalah yang berkaitan dengan peningkatan perpustakaan, negara tetap hampir tidak berubah sejak pendirian universitas ( 2 hingga 3 dekade lalu). Menolak saran dari administrator dan kurangnya transparansi adalah dua masalah utama yang menyebabkan ketidakefektifan dewan universitas tersebut.

\section{METODE PENELITIAN}

Penelitian ini menggunakan pendekatan deskriptif. Jika data yang diperoleh sudah terkumpul kemudian diklasfikasikan menjadi dua kategori data, yaitu kategori data kualitatif dan kategori data kuantitatif. Data kualitatif berupa kata-kata atau simbol, sedangkan data kuantitatif merupakan data yang berupa angka. Penelitian ini menggunakan metode :

\section{Observasi}

Observasi merupakan suatu cara untuk mengumpulkan data dengan mecermati dan mendokumentasikan secara sistematik fakta-fakta yang diamati (Supardi, 2006).

\section{Wawancara}

Wawancara adalah percakapan dua orang untuk bertukar informasi dan ide melalui tanya jawab sehingga dapat ditemukan maksud dalam suatu tema tertentu (Sugiyono, 2011).

Wawancara dilakukan dengan mengajukan beberapa pertanyaan yang ditujukan kepada informan, dalam hal ini bisa dilakukan dengan pengunjung dan pustakawan.

\section{Waktu}

Penelitian ini dilakukan di Perpustakaan Puspa Cendekia SD Negeri Pakis 1 yang berlokasi di J. Magelang-Kopeng Km. 17 Pakis Magelang, dari tanggal 1 s.d 15 Oktober 2019.

\section{HASIL PENELITIAN DAN PEMBAHASAN}

Berdasarkan hasil observasi diketahui bahwa perpustakaan Puspa Cendekia berdiri pada tahun 2008. Perpustakaan Puspa Cendekia memiliki luas 9 $\mathrm{x} 7 \mathrm{~m}^{2}$ yang terdiri dari ruang koleksi, ruang referensi, ruang audio visual, ruang baca, dan ruang sirkulasi. Kemudian pada tahun 2016 ada penambahan ruang baca dengan luas $2 \times 7 \mathrm{~m}^{2}$. Tahun 2017 dibangun 2 buah gazebo, masing-masing dengan ukuran $3 \times 7 \mathrm{~m}^{2}$ bisa juga digunakan untuk tempat baca diluar ruangan. Dengan total luas $17 \times 7 \mathrm{~m}^{2}$ cukup untuk ditempati 40 orang. Menurut SNP (Standar Nasional Perpustakaan) ketentuan untuk sekolah dasar/madrasah ibtidaiyah jika memiliki 3 sampai 6 rombongan belajar, luas gedung sekurang-kurangnya $72 \mathrm{~m}^{2}$. Jadwal peminjaman buku 2 kali dalam seminggu. Namun, diluar jadwal tersebut siswa diperbolehkan mengunjungi perpustakaan. 
Perpustakaan Puspa Cendekia dikelola oleh 1 orang pustakawan yang berijazah D2 IImu Perpustakaan.

Demi tercapainya pembelajaran yang optimal serta mampu melayani pemustaka dengan cepat dan tepat maka pada tahun 2016 Perpustakaan Puspa Cendekia mulai menggunakan sistem otomasi dalam pengolahan dan pelayanan dengan menggunakan software SLIMS. Dengan adanya sistem otomasi pelayanan peminjaman menjadi cepat sehingga pemustaka tidak perlu berlama-lama antri untuk meminjam bahan pustaka.

Hal-hal yang mempengaruhi minat pemustaka berkunjung ke perpustakaan :

a. Perpustakaan memiliki koleksi yang cukup lengkap

b. Pelayanan yang ramah terhadap pengunjung

c. Ruangan perpustakaan nyaman

d. Fasilitas yang disediakan memadai

e. Perpustakaan memberikan reward kepada pembaca terbanyak setiap triwulan

f. Lokasi strategis

g. Penataan buku pada rak sesuai dengan nomor klasifikasinya

Untuk mencapai kondisi tersebut, pihak perpustakaan harus melakukan berbagai upaya seperti, pendekatan dengan siswa, memberikan promosi, melayani keinginan dan kebutuhan siswa akan informasi. Apabila hal tersebut dapat dilakukan dengan baik, mereka akan mendapatkan nilai tambah dari keberadaan perpustakaan tersebut (Suwarno, 2009).

Menurut Dahlan dalam bukunya yang berjudul Apa yang membuat Perpustakaan Nyaman ada beberapa faktor yang membuat betah berkunjung ke perpustakaan adalah (Dahlan, 2019) :

1. Nyaman, artinya ruangan perpustakaan dalam keadaan bersih dan sejuk.

2. Kondisi ruangan yang memadai, artinya keter- sediaan berbagai macam koleksi yang up to date dan bermutu.

3. Kondisi lingkungan sosial yang kondusif, artinya pustakawan berperilaku ramah, tersedianya tempat untuk membaca, tersedianya tempat untuk melakukan kegiatan belajar mengajar atau tempat untuk berdiskusi

Tabel 1. Data Kunjungan Siswa Juli-September 2019

\begin{tabular}{|l|c|c|c|}
\hline \multicolumn{1}{|c|}{ KELAS } & JULI & AGST & SEPT \\
\hline KELAS I & 35 & 75 & 80 \\
\hline KELAS II & 41 & 67 & 71 \\
\hline KELAS III & 13 & 53 & 73 \\
\hline KELAS IV & 24 & 82 & 94 \\
\hline KELAS V & 17 & 62 & 79 \\
\hline KELAS VI & 27 & 51 & 80 \\
\hline Jumlah & 157 & 390 & 477 \\
\hline Rata-rata per hari & 26 & 65 & 80 \\
\hline
\end{tabular}

Sumber : Buku Laporan Tahunan Perpustakaan Puspa Cendekia SD Negeri Pakis 1 Tahun 2019

Grafik Kunjungan Siswa ke Perpustakaan Puspa Cendekia Juli-September 2019

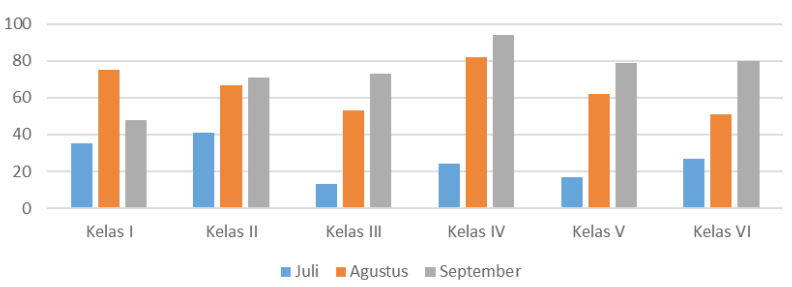

Gambar 1. Grafik Kunjungan Siswa ke Perpustakaan Puspa Cendekia Juli-September 2019

Dari grafik diatas menunjukkan adanya peningkatan jumlah pengunjung setiap bulan. Kelas 6 menduduki tingkat pertama jumlah pengunjung terbanyak. Hal ini dikarenakan kelas 6 dituntut aktif 
mencari informasi yang menunjang mata pelajaran. Kelas 1 jumlah pengunjungnya paling sedikit karena masih dalam tahap pengenalan perpustakaan. Meskipun banyak juga siswa kelas 1 yang sudah mulai meminjam buku dibawa pulang untuk belajar membaca.

Jumlah koleksi bahan pustaka yang dimiliki sangat mempengaruhi minat kunjung pemustaka ke perpustakaan. Apabila bahan pustaka yang dibutuhkan pemustaka tidak tersedia maka jumlah pengunjung pastinya akan berkurang. Perpustakaan Puspa Cendekia memiliki koleksi buku-buku fiksi/non fiksi, buku referensi, buku penunjang mata pelajaran, buku teks pelajaran, CD Pembelajaran, Peta, Globe, Majalah, Surat kabar. Semua koleksi tersebut bisa digunakan oleh pemustaka, baik guru maupun siswa.

Tabel 2: Data koleksi bahan pustaka yang dimiliki Perpustakaan Puspa Cendekia

\begin{tabular}{|c|l|c|}
\hline NO & \multicolumn{1}{|c|}{ JENIS KOLEKSI } & JUMLAH (EKS) \\
\hline 1 & Fiksi/Non Fiksi & 5172 \\
\hline 2 & Referensi & 962 \\
\hline 3 & Buku Penunjang (Panduan Pendidik) & 358 \\
\hline 4 & Buku pelajaran & 5497 \\
\hline & Jumlah & 11989 \\
\hline
\end{tabular}

Sumber : Buku Induk Perpustakaan Puspa Cendekia

Tabel 3: Data koleksi berdasarkan klasifikasi

\begin{tabular}{|c|l|c|}
\hline NO & \multicolumn{1}{|c|}{ KLASIFIKASI } & JUMLAH (EKS) \\
\hline 1 & 000 (KARYA UMUM) & 474 \\
\hline 2 & 100 (FILSAFAT) & 577 \\
\hline 3 & 200 (AGAMA) & 1062 \\
\hline 4 & 300 (ILMU SOSIAL) & 1084 \\
\hline
\end{tabular}

\begin{tabular}{|c|c|c|}
\hline 5 & 400 (BAHASA) & 1441 \\
\hline 6 & 500 (ILMU MURNI) & 1079 \\
\hline 7 & 600 (TEKNOLOGI) & 1357 \\
\hline 8 & 700 (KESENIAN) & 912 \\
\hline 9 & 800 (KESUSASTRAAN) & 3028 \\
\hline 10 & 900 (SEJARAH) & 975 \\
\hline & JUMLAH & 11989 \\
\hline
\end{tabular}

Sumber : Buku Induk Perpustakaan Puspa Cendekia

Tabel 4 : Data buku yang dipinjam bulan agustus 2019

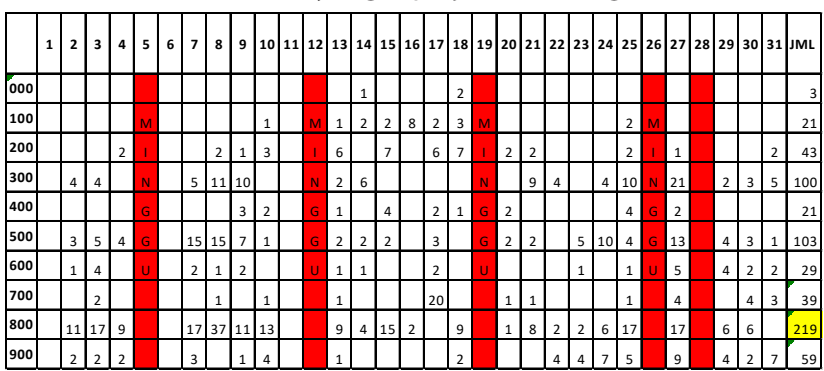

Sumber : Laporan bulanan perpustakaan Puspa Cendekia

Dari data diatas menunjukkan bahwa klasifikasi 800 (Kesusatraan) merupakan koleksi terbanyak yang dimiliki perpustakaan dan paling banyak diminati pemustaka.

Semakin berkembangnya perpustakaan maka muncul pula beberapa kendala/masalah yang dihadapi, antara lain :

1. Perlu penambahan jumlah eksemplar koleksi buku

2. Belum tersedianya jaringan internet

3. Penambahan petugas perpustakaan

4. Dana anggaran BOS sebesar $5 \%$ untuk perpustakaan belum terealisasi sepenuhnya

5. Terjadinya trouble pada layanan peminjaman dan pengembalian

6. Kurangnya kesadaran pengguna dalam 
pengembalian buku yang selesai dibaca tidak pada tempatnya.

\section{E. PENUTUP}

\section{Simpulan}

a. Minat pemustaka berkunjung ke perpustakaan dipengaruhi oleh beberapa faktor, diantaranya yaitu, adanya koleksi yang cukup lengkap, pelayanan yang ramah terhadap pengunjung, ruangan perpustakaan nyaman, fasilitas yang disediakan memadai, perpustakaan memberikan reward kepada pembaca terbanyak setiap triwulan.

b. Kendala yang dihadapi, belum tersedianya jaringan internet, perlunya penambahan jumlah koleksi buku, terjadi trouble pada layanan peminjaman dan pengembalian, dana anggaran BOS sebesar 5\% untuk perpustakaan belum terealisasi sepenuhnya

c. Solusi yang diberikan Perpustakaan Puspa Cendekia dengan mengajukan anggaran dana untuk pemenuhan kebutuhan perpustakaan, baik koleksi buku, sarpras, serta penambahan tenaga perpustakaan agar aktivitas perpustakaan dapat berjalan lancar

\section{Saran}

a. Fasilitas berupa kursi dan meja baca kecil yang berada di ruang sirkulasi sebaiknya ditambah

b. Perlu pengadaan komputer untuk sistem OPAC

c. Menambah petugas perpustakaan

d. Penambahan koleksi buku dengan judul baru

e. Meningkatkan pelayanan dengan sistem otomasi

f. Penggunaan media audio visual lebih ditingkatkan lagi

\section{DAFTAR PUSTAKA}

Dahlan, A. (2019). Dahlan, Ade. 2006. Apa yang Membuat Perpustakaan Nyaman? FIB-UI. 152.118.24.150/articles.php?article_id=10
Fakoya-Michael, S. A., \& Fakoya, M. B. (2020). Library usage by university accounting students: a comparison of contact and open distance learning institution in South Africa. Journal of Academic Librarianship, 46(1), 102093. https:// doi.org/10.1016/j.acalib.2019.102093

Muthanna, A., \& Sang, G. (2019). State of University Library: Challenges and Solutions for Yemen. Journal of Academic Librarianship, 45(2), 119-125. https://doi.org/10.1016/j. acalib.2019.01.010

Sugiyono. (2011). Metode Penelitian Kuantitatif, Kualitatif, dan R\&D. Alfa Beta.

Supardi, M. . (2006). Metodologi Penelitian. Yayasan Cerdas Prees.

Suwarno, W. (2009). Psikologi Perpustakaan. Sagung Seto. 